\title{
The hydrogeological problems of disused mines in Olgiate Molgora (LC)
}

\author{
L. Longoni \& M. Papini \\ Politecnico di Milano, Italy
}

\begin{abstract}
The object of this work is to evaluate more effective methodological approaches to face problems concerning areas affected by the presence of disused mining sites. Some years after the closure of mines, various problems as a consequence of disuse have come to light, and also, possibilities to use this resource with touristic and cultural aims have often been ignored. From the moment they have been closed mines can cause several problems, both for safety of the mine and of the neighbouring areas (downfalls, collapse of the vault, variations in the underground circulation, etc.) so it is necessary to evaluate more suitable techniques in order to maintain mines and prevent risks related to their presence. In order to deepen this subject we studied with particular detail a pilot area representative of the described problems: the Pelucchi Mine sited in Olgiate Molgora (LC). Several problems occurred in this abandoned area: the most important being that galleries have been troubled by water infiltration phenomena, starting from the lower part of the cavity. Previously the water was pumped away by the water pipeline until the water level was within acceptable limits, but when the extraction ceased water filled the cavities and saturated all materials around. This event caused a progressive alteration of the modalities of the underground water circulation, which in the future could cause instability phenomena on the surface and in the area near to the caves. In order to check the stability condition of these mines several analyses, either direct or indirect, have been made. Indirect analysis was made with the use of Satellite Radar Interferometry, to make a complete monitoring of surface movements (subsidence due to the collapse of caves), useful for the mine collapsed forecasting.

Finally a phenomenological model has been made to define risk scenarios, necessary for Civil Protection aims and for the instability phenomena analysis.

Keywords: water circulation, mines, risk.
\end{abstract}




\section{Introduction}

The closure of a mine triggers many problems regarding safety and risks. In fact the closure of a mine implies the ceasing of mining activities, and consequently of all the maintenance activities, in particular dewatering by pumping: consequently the water level increases and causes different problems for the stability of underground spaces. The case described in this paper deals with dismiss of Pelucchi mine located in Olgiate Molgora, near Lecco. The Pelucchi mine was one of the biggest mines in the Lecco zone for the extraction of cement marls; production ceased in 1954 and since then the mine has been under maintenance. The mines have been used for a long time as a water reservoir for the water pipeline. When the pumping ceased, all seven levels of the mine have been filled with water; after this, all water storage activities were definitively abandoned. This site has been analyzed as a guideline for the use of different kinds of monitoring systems, either direct (like geomechanical and hydrogeological surveys) or indirect (like Satellite Radar Interferometry). Every method has been applied and the results have been compared in order to forecast instability phenomena. Moreover, a phenomenological model has been defined to investigate all possible risk scenarios that could occur in and outside the mine.

\section{Geological and geomorphologic context}

Olgiate is in North of Italy, $20 \mathrm{~km}$ south of Lecco and few kilometres from Adda river. The area is characterized by sedimentary sequence of cretacic rocks, referring to Scaglia and Bergamo Flysch Formations, which locally show limestone-marl levels, even with thickness of ten meters. Quaternary sediments (colluvial and alluvial deposits) are diffused and continuous, covering most parts of the surface rock, although there's no difficulty in understanding underground geo-structural characteristics. Caves develop along the reversed side of Lissolo Synclinal, with South alignment and having axial plane with WNW-ESE direction. The most important tectonic features that interest Pelucchi mine are two sub-vertical faults with $\mathrm{N}-\mathrm{S}$ direction.

\subsection{Map of the mine}

In order to apply all geomechanical classifications the mine has been divided in to different tracts with homogeneous mechanical characteristics. It has been easy to divide these mines by the structural conditions of the rock mass and by the reduced presence of sets of joints (three sets of joints in the marls and one set bedding - in the flysch). Homogeneous tracts that resulted from the structural analysis have been called: North Entry (INNO), South Entry (INSU), Pelucchi Gallery (PELU), Fault (FAGL), Piave Gallery (PIAV), West Piave Gallery (PIOV), Final Buttero Gallery (BUFI), West Buttero Gallery (BUOV) and East Buttero Gallery (BUES). In the map below (fig. 1) it is possible to see all these tracts with their position in the mine. 


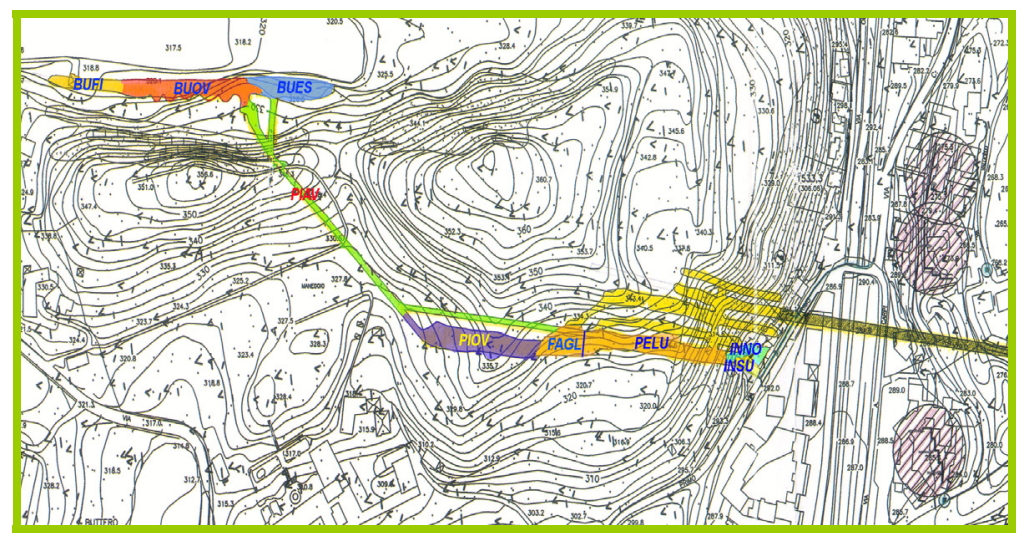

Figure 1: $\quad$ Tracts of the Pelucchi Mine.

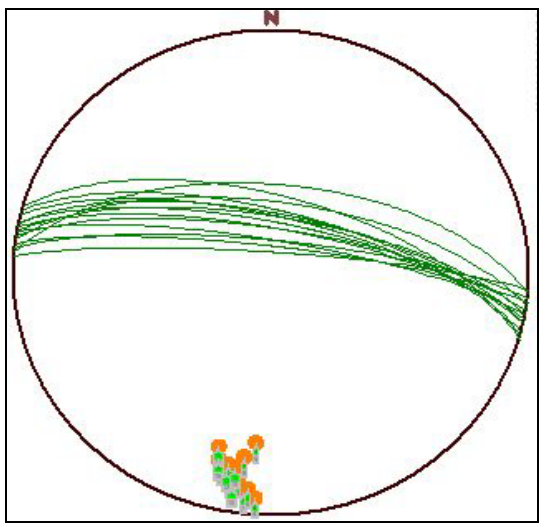

Figure 2: Example of stereographic projection (Schmidt net).

\subsection{Geological survey}

First, the direction of strata and joints presented in the mine has been determined. It has been possible to define geometries of discontinuities with respect to the direction of the cave (East-West direction), obtaining a good base for an evaluation of its stability. The section made by massive marl has bedding strata with dip of $5^{\circ}$ and inclination of $60^{\circ}$ and two joints sets, K1 with dip of $270^{\circ}$ and inclination of $75^{\circ}$ and $\mathrm{K} 2$ with dip of $15^{\circ}$ and inclination of $35^{\circ}$. Spacing shows very high values in all three sets (S0, K1, K2), generally of 3-4 meters, and without any filling material (almost all the cracks are closed). The part made by thinly stratified flysch shows a dip direction similar to the marl one, with spacings of about $5 \mathrm{~cm}$ filled by clay. All data obtained by the survey of all sets have been mapped with stereographic projections in a Schmidt net (as it is possible to see in the example of fig. 2). It is necessary to say that it's not been 
possible to consider all features of discontinuities in all tracts in the mine: for example in some tracts (INSU, FAGL, BUFI, BUOV) it proved very difficult to take joint planes in a significant number because of the high spacing between discontinuities (more than 4 meters); in other tracts (e.g. PIOV) it proved very dangerous to make a survey, because of a big rock fall that intersected the tract. In order to know the stability of the rock mass several geomechanical classification methods have been applied in this mine. Methods applied for this case have been the Q-system [7] and the Geological Strength Index [8] for the knowledge of geomechanical quality and the Modified Rock Engineering System [9] to know the Risk Index.

Results (table 1) present general good geomechanical conditions for all tracts associated with the massive marl and bad conditions for the parts with thin stratified Flysch. Risks of rock falls are, as would be expected from the stability assessment, concentrated in tracts where there are Flysch lithology outcrops, underlining that massive marl is stable.

Table 1: $\quad$ Values of results for Q-system, GSI and MRI.

\begin{tabular}{|c|c|c|c|}
\hline & $\begin{array}{c}\text { Q-system } \\
\text { values }\end{array}$ & GSI values & MRI values \\
\hline INSU & 1.5 & 32 & 22.2 \\
\hline INNO & 7.5 & 45 & 22 \\
\hline PELU & 10 & 60 & 23.4 \\
\hline FAGL & 6.6 & 52 & 26.4 \\
\hline PIAV & 0.3 & 22 & 61.2 \\
\hline PIOV & 2.2 & 37 & 24.1 \\
\hline BUFIN & 2.2 & 50 & 20 \\
\hline BUOV & 20 & 62 & 20.9 \\
\hline BUES & 61 & 80 & 20.9 \\
\hline
\end{tabular}

\subsection{Hydrogeological survey}

Direct analysis was also used to study the hydrogeological system of Pelucchi area; it is possible to find two sub-systems: a superficial alluvial system and a complex underground system that links tunnels with external water wells. In general, the water level inside Pelucchi mine is correlated with atmospheric water phenomena. From previous data it is reported that after long rain periods the water level rises to the first level of galleries and overrides it. An important event is the December 2002 one, when after a 10-day rainy period the water level rose to $20 \mathrm{~cm}$ above the first level ground, flowing out of the principal access to the mine and flooding the road. In order to verify the correlation between rains and water level and then for monitoring the water level in the Pelucchi tunnels, two pressure sensors (designed for submersible measurement) were installed in 
November 2006. The first one (sensor A) has been installed in the well which links first level with other levels in the Pelucchi part, while the second one (sensor B) has been installed in the well that links three levels of the Buttero side of the mine.

In fig. 3 variations of water level in the period between November 2006 and March 2007 are represented. In relation to sensor A only small variations in water level were observed until 3-7-2007, probably due to a rise in the flux from Piave linking tunnel. After this date, the position of sensor was changed, and until 1-6-2007 it revealed a lowering $(135 \mathrm{~cm})$ with respect to the first measured level, while in 6-7-2007 it revealed a rise of $88 \mathrm{~cm}$. The comparison between sensors A and B reveals that there are not any common features in water level movements: the only matches available are raising period ones, when (2-8 May 2007 and from June 2007) water level had a rise in both parts of the mine. However, it is important to note that the entity of rising was very different between $\mathrm{A}$ and $\mathrm{B}$ points (some $\mathrm{cm}$ for sensor $\mathrm{B}$ and $150 \mathrm{~cm}$ for sensor $\mathrm{A}$ ). A conclusion would be that in the two examined tunnels in and out water flows are very different.

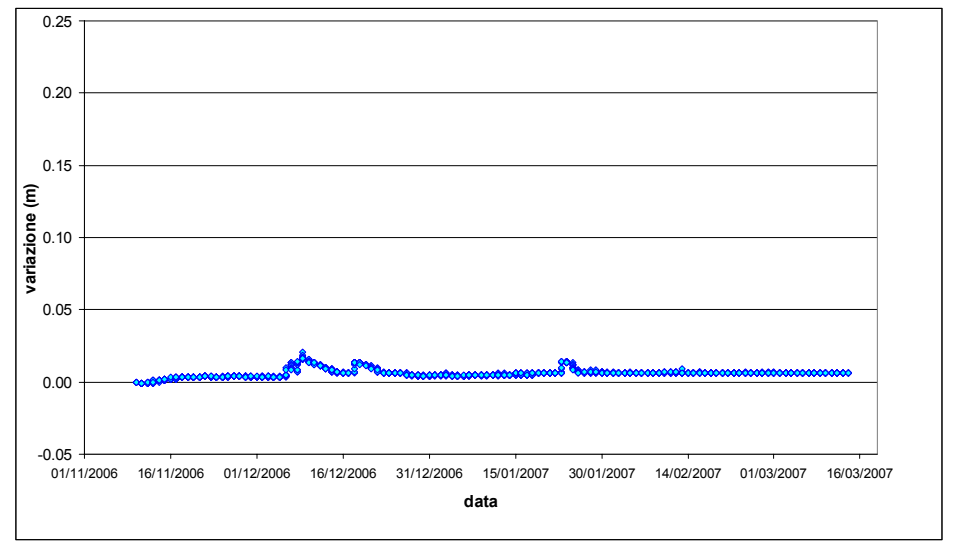

Figure 3: Water level flows in Pelucchi tunnel (sensor A) in the period 1-11$2006-14-3-2007$.

\subsection{Indirect analysis}

In order to evaluate geological risk connected to the presence of hydrogeological diseases, ordinary field surveys have been integrated with the Permanent Scatters (PS) Technique, which is largely used for the monitoring of subsidence or uplift. PS technique analyzes thousands of square kilometers of territory within an extremely short time scale. The Permanent Scatters Technique is a tool that detects, measures and monitors ground movement, using satellite SAR (Synthetic Aperture Radar) data. The PS technique takes conventional differential InSAR a step forward, by identifying single benchmarks, often referred to as permanent scatters and reconstructing their displacement history. 
PS are radar targets that are located across the earth's surface and can be monitored by satellites. It is possible to detect and measure millimetre variations in the sensor- target distance, over time. PS correspond to objects on man-made structures (bridges, dams, buildings, etc.) as well as to stable natural reflectors. This technique has been applied in the mine site to monitor ground movements. As it is possible to see, the PS in the area correspond to buildings; the presence of vegetation near the mines does not permit any other reflectors. It has been possible to estimate the displacement rate for which the precision can be as good as $0.1 \mathrm{~mm} /$ year and reconstruct the displacement history of the PS.

Analyzing track nr.251 no movement has been found (fig. 4). Other data (track 208 and 480) show that the area is subjected to uplift; track 480 instead highlights subsidence. The different movements found in another two tracks allow saying that for the Olgiate area the technique of PS doesn't provide necessary data to understand subsidence or uplift phenomena. It is also possible that no important movement has been detected, for the absence of radar targets with PS characteristics directly on the surface correspond to underground presence of caves, being all the area covered by vegetation. In fact houses sited on the north part of the area are distant from the mine and consequently it proves very difficult to correlate those points with hydrogeological and structural changes induced by the presence of mines.

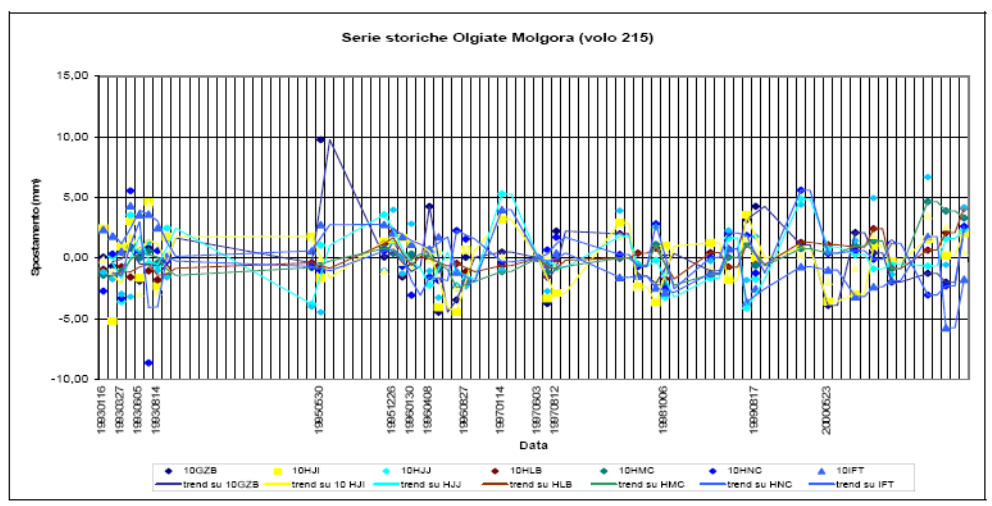

Figure 4: $\quad$ Historical series for Pelucchi galleries from track 215.

\section{Phenomenological models}

A phenomenological model has been made to define risk scenarios, necessary for Civil Protection aims and for the instability phenomena analysis. Five scenarios have been reconstructed.

\section{Scenario 1}

The first level, that is the only accessible one in Pelucchi mines, develops inside a bank of marls that is followed by a highly stratified flysch (filled with clay). In 
particular the first level develops through compact marls and flysch. There is one outcrop on the left part of the gallery, characterized by the presence of thinstratified marl strata interlayered with centimetric levels of clay. In the part characterized by the presence of massive marl there is a low probability of rockfalls, while in the part of the mine characterized by the presence of flysch the probability of rockfalls is more than $50 \%$. This fact is demonstrated by previous collapses inside caves, as is possible to see in fig. 5. So this scenario seems to be probable, and it is possible for another collapse to occur near the roof or the left wall. However, no consequence, outside of the mine, is to be considered by such collapses in the flysch part; this scenario should be considered only if, for example, these tunnels were to be used for touristic aims.

\section{Scenarios 2 and 3: sudden collapses of sects that divide caves from the} surface and sudden and extended collapses of sects and walls of tunnels

These scenarios have been set under the same title because they both address various kinds of collapses inside the caves. Such collapses can be due to the same causes, and the part of the mine where they take place would determine several effects on the stability. Factors that could cause these scenarios are similar to the ones in case 1: fracturation of rock mass, presence of clay interlayered with marls. So the difference between these two cases and case 1 is the dimension of the phenomenon: case 2 and 3 contemplate the collapse of considerable parts of caves.

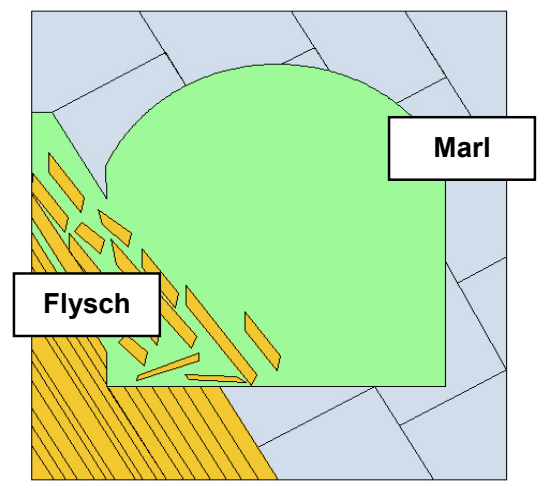

Figure 5: $\quad$ Scenery 1: Rockfall on flysch part (brown).

In particular, scenario 2 contemplates collapses that interest the surface (roof of level 1), while scenario 3 contemplates underground levels.

Possible consequences of both scenarios would be:

- Sudden water flow out of tunnels along the slope, with possible flooding of the inhabited area (fig. 6);

- Sudden pumping of water in second level along the slope, with possible flooding of the inhabited area. (fig. 7). 
Geomechanical survey suggests that only where flysch constitutes most part of the cave can collapses of such entity occur: in fact in these tracts several collapses have already happened without any consequence.

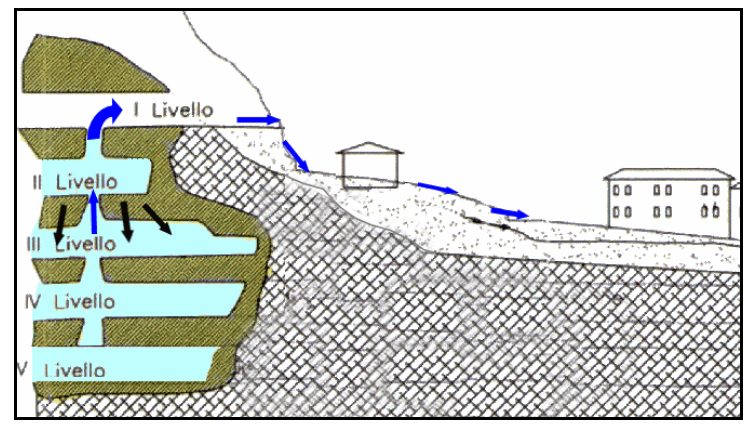

Figure 6: $\quad$ Scenario 2: Waterflow out of galleries.

The probability of such an event happening of could be known after an assessment of the lower levels, which can't be investigated with a direct survey, as they are filled with water. It is difficult to know the position of flysch in the underground levels because, as was said above, they are filled with water and it is very difficult to make a direct survey. So it is impossible to evaluate exactly what is the percentage of risk of underground collapse. However, the risk of a collapse of the roof over the first level, although it is a remote possibility, is always to be considered.

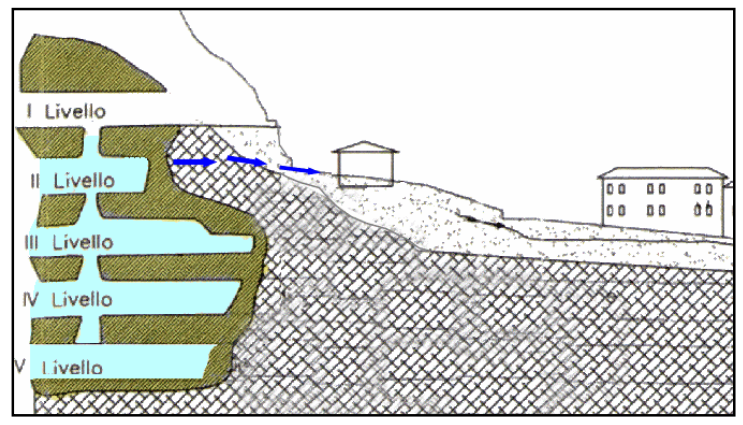

Figure 7: $\quad$ Scenario 3: Pumping of water present in galleries, with possible flooding.

\section{Scenario 4: flood on the slope}

This scenario could be caused by the infiltration of water inside the fractured rock mass and inside glacial and fluvioglacial overlaying deposits. Such infiltrations are made possible by the fractured rocks, caused also by alteration (considering the low presence of surface sediments). 
A possible consequence of infiltration of water should be a flood that would reach the basements of houses placed on the slope under the mine. This has already happened in the past, where the basements of houses in Valicelli (an Olgiate Molgora quarter) required draining works in order to bring water out of the civil structures.

As these past events demonstrate, this scenario seems to be very realistic, so it would be necessary to drain all the area around the mines. The probability of this scenario happening is high.

\section{Scenario 5: rising water level after long period of rainfalls}

This scenario could be caused by progressive saturation of the lower levels of tunnels, until they reach the surface level. The hydrogeological statement of the area near mines suggests that after intense and prolonged rain the water level can easily reach the first level. The first consequence can be water flow out of tunnels, and then on the slope under mines (fig. 8). Even this event is very probable, already happening in 2002, when water levels reached the road that passes over the entrance of the mine.

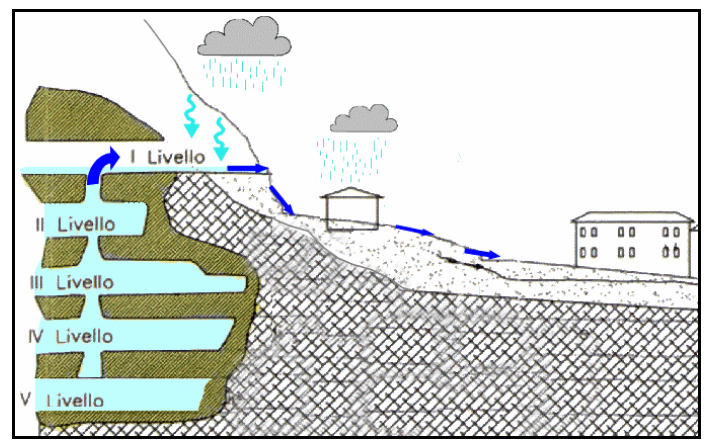

Figure 8: $\quad$ Scenario 5 - Flooding from entrance to the slope under the mine.

\section{Conclusion}

Geological and hydrogeological surveys proved to be helpful to determine the structural settlement of mines and water circulation in and outside mines. Knowing percentage of stability inside caves and the way water circulates proved to be very important to define a risk analysis, and after that to build up various possible scenarios that can occur, in order to create a phenomenological model, necessary to plan an intervention model for civil protection field works.

Moreover, the PS technique proved to be a good remote sensing instrument, thanks to its high reliability in identifying and monitoring ground deformations also (and first of all) in a large scale. However, note that for good results it is necessary to know very well the geological settlement of the area that is to be surveyed. In fact only with appropriate studies it is possible to know whether PS 
will have good significance relative to a considered phenomenon and if they will give information useful for major comprehension of the case studied.

It is important to say that morphology of the area, presence of vegetation and position of human settlement, create a non-homogeneous distribution of PS points in the area. So in cases like this one it can prove very difficult to study natural phenomena and eventual movements in the area. As an obvious consequence, in critical areas similar to this one, and for other studies in this field, it is suggested to place artificial reflectors where it is not possible to find any other pre-existent fixed point, in order to permit a complete survey of the area (especially of critical points).

\section{References}

[1] Comune di Olgiate Molgora (2005): "Labirinti sommersi: la cementeria del Fabbricone e le gallerie Pelucchi: un caso di archeologia industriale ad Olgiate Molgora". A cura di Lorenzo Brusetti, Massimo Cogliati e del Gruppo Sommozzatori Alme - Olgiate Molgora. - pp. $85+3$ tav

[2] Penati M., Lanfranconi P. (1999): "Studio idrogeologico per lo sfruttamento delle acque presenti nelle gallerie della ex-miniera Pelucchi nel Comune di Olgiate Molgora (LC)" STUDIO GEOPLANET - pp. $20+5$ tav.

[3] Bieniawski Z.T. (1976) - Rock mass classification in rock engineering. In: Bieniawski (ed.), Exploration for rock engineering procs. Of the Cape Town symp., 1, 97-106.

[4] Bieniawski Z.T. (1989) - Engineering rock mass classifications. Wiley Publ.

[5] Hack R. (1997) - Rock mass strength by rock mass classification. South African Rock Eng. Congr. (SARES), Johannesburg, 346-356.

[6] Papini M., Granito A. e Scesi L. (1998) - Caratterizzazione geomeccanica degli ammassi rocciosi: un approccio statistico. Quaderni di Geologia Applicata, 5(2), 41-47.

[7] Barton N., Lien R., Lunde J. (1974) - Engineering classification of rock masses fort he design of tunnel support. Rock mechanics 6 (4)

[8] Hoek E., Marinos P., Benissi M. (1998) - Applicability of the geological strength index (GSI) classification for very weak and sheared rock masses. The case of the Athens Schist formation. Bulletin of Engineering Geology and the Environment, 57

[9] Papini M., Scesi L., Gattinoni P. (2002) - Valutazione del rischio geologico nelle gallerie minerarie:applicazione del Modified Rock Engineering System. GEAM 1, 2002, 89-96 